\title{
Bronchus cardiacus accessorius dexter
}

\author{
Derek Roebuck • Clare A. McLaren
}

Received: 28 July 2009 / Accepted: 18 August 2009/Published online: 17 November 2009

(C) Springer-Verlag 2009

A 3-month-old boy underwent flexible bronchoscopy with bronchography for evaluation of airway compression associated with absent pulmonary valve syndrome. This showed a blind-ending bronchus, arising from the medial aspect of the right main bronchus opposite the origin of

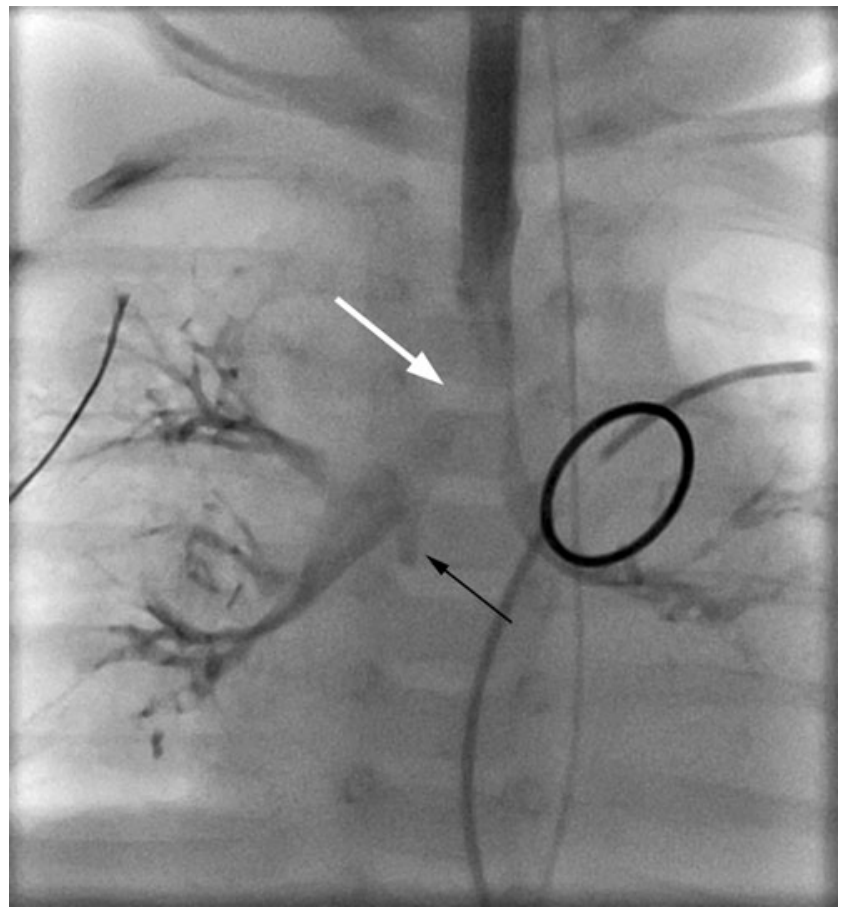

Fig. 1 Bronchography

D. Roebuck $(\bowtie) \cdot$ C. A. McLaren

Department of Radiology,

Great Ormond Street Hospital for Sick Children,

Great Ormond Street,

London WC1N 3JH, UK

e-mail: roebud@gosh.nhs.uk the right upper lobe bronchus (black arrow) (Fig. 1). There was extrinsic compression of the carina (white arrow) due to enlargement of the pulmonary arteries. The finding was confirmed by contrast-enhanced CT (arrow) (Fig. 2).

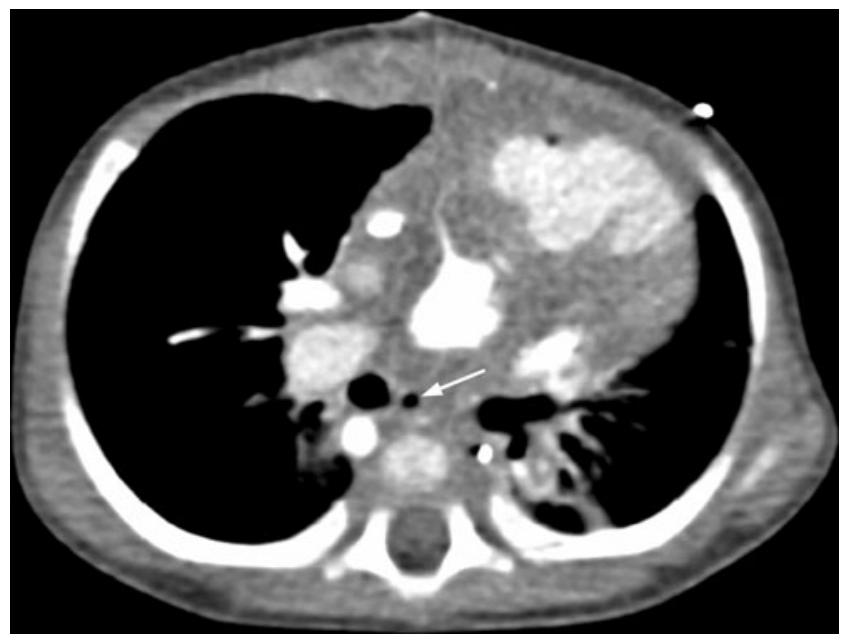

Fig. 2 Contrast-enhanced CT

Bronchus cardiacus accessorius dexter is a rare anomaly, detected at less than $0.1 \%$ of adult bronchoscopies $[1,2]$. It may coexist with other anomalies, as in this patient, but is rarely symptomatic $[1,2]$.

\section{References}

1. Barzo P, Nagy B (1999) Bronchus cardiacus accessorius dexter. Diagn Ther Endosc 5:211-217

2. Mangiulea VG, Stinghe RV (1968) The accessory cardiac bronchus. Bronchologic aspect and review of the literature. Dis Chest 54:433-436 